\title{
Impact of the various factors on survival of tracheoesophageal fistula patients: A prospective study of 16 patients
}

\author{
Shailendra Pareek ${ }^{1}$, Lalit Kumar Raiger ${ }^{2}$, Yogendra Singhal ${ }^{3, *}$ \\ ${ }^{1}$ Consultant, ${ }^{2}$ Professor, ${ }^{3}$ Assistant Professor, Dept. of Anaesthesia, ${ }^{1}$ Narayana Hrudayalaya, Jaipur, Rajasthan, 2,3RNT Medical \\ College, Udaipur, Rajasthan, India \\ *Corresponding Author: Yogendra Singhal \\ Email: singhalyogi@yahoo.co.in
}

Received: $21^{\text {st }}$ May, 2018

Accepted: $8^{\text {th }}$ June, 2018

\begin{abstract}
Introduction: Tracheoesophageal fistula (TEF) is one of the common congenital anomalies presented at birth. Management of TEF is a challenging task as outcome of these cases not only depends on surgeon and anaesthesiologist's skills but also depends on various factors associated with new born. This prospective study evaluates the association of various factors on survival of TEF patients.

Materials and Methods: 16 newborn patients in a calendar year were enrolled in this prospective study and impact of various factors like age, weight, parity of mother, associated congenital anomalies and family history, mode of delivery, place of delivery, associated hydramnios and type of TEF were evaluated on the survival of neonates born with TEF.

Results: Male, female ratio was equal. Patient with birth weight $>2.5 \mathrm{~kg}$ had higher survival rate (100\%) compared to patient $<2.5 \mathrm{~kg}$ weight $(23.08 \%)$. No other factors significantly influence the survival rate of neonates with TEF.

Conclusion: Birth weight remains the single most important predictor of mortality among TEF patients, as suggested with Waterston risk classification.
\end{abstract}

Keywords: Tracheoesophageal fistula, Birth weight, Neonates, Waterston classification.

\section{Introduction}

'Esophageal atresia \& tracheoesophageal fistula (TEF)' is one of five major surgical manifestations of first week of life including congenital diaphragmatic hernia $(\mathrm{CDH})$, omphalocele, gastroschisis, intestinal obstruction and meningomyelocele. In these $\mathrm{CDH}$, omphalocele and meningomyelocele are presented at birth while TEF and intestinal obstruction take hours or days to manifest.

Incidence of TEF is 1:3000 live birth, approximately $87 \%$ consist of a fistula from distal trachea to the esophagus and a blind proximal esophageal pouch. ${ }^{1}$ It occurs due to embryological defect results from imperfect division of the foregut into the anteriorly positioned larynx, trachea and posteriorly positioned esophagus which occurs at the fourth and fifth week of intrauterine life.

These cases are usually present with aspiration pneumonitis and respiratory distress due to aspiration of gastric content, secretions and breastfed milk from a blind upper esophageal pouch into trachea. Dehydration results from the fact that the proximal esophagus doesn't communicate with stomach. It demands early diagnosis, resuscitation, treatment and emergency surgical correction.

Association of congenital anomalies worsens the outcome (as described by Waterston's classification and later by spitz in 1990). ${ }^{2}$

Along with early diagnosis and management, anaesthetic management is also challenging because these neonates usually present with low birth weight, associated congenital anomalies, respiratory tract infection, risk of hypothermia and dehydration. Even after good anaesthetic management and surgical correction neonates need skilled nursing staff, besides all modern neonatal intensive care facilities.

We planned this study to evaluate the association of different factors on survival on TEF patients.

\section{Materials and Methods}

After institutional ethical committee approval, this prospective study was carried out in MB Govt. Hospital, RNT Medical College, Udaipur which included the neonates scheduled for repair of esophageal atresia and tracheoesophageal fistula in routine and emergency operation theatres.

All the patients were enquired about obstetric history (parity, previous born child, week of gestation, presence of hydramnios, mode of delivery: (vaginal/assisted/caesarean, delay in birth), clinician notes (including APGAR score, weight at birth, need for resuscitation), mother's medical/drug history, family history of having any congenital anomalies, time of diagnosis after birth and by whom, any feed/fluid given in between birth and diagnosis, presenting complaints, delivery at institute or at periphery and measures taken before presenting to hospital and treatment given after admission were noted.

After getting informed consent, baby was examined thoroughly including complete physical examination, routine laboratory investigation $(\mathrm{CBC}$, BT, CT, X-ray chest) including neonatologist examination record and other relevant investigations 
according to manifestations of other congenital anomalies.

Patients with preoperative pneumonitis were optimized with medical intervention (e.g., oxygenation, humidification, physiotherapy, bronchodilators, cortisone, antibiotics, i.v. fluids and temperature regulation, etc.) before taking for surgery. Consent from patient's parents/attendants was taken and crossmatched blood was made available in operation theatre.

Intraoperative fluid therapy included deficit correction, maintenance fluid $(4 \mathrm{ml} / \mathrm{kg} / \mathrm{hr}$ of $5 \%$ dextrose with $\mathrm{N} / 4$ normal saline) and blood if needed. Baby was wrapped in cotton layer to prevent hypothermia.

After securing a peripheral line with 24 gauze intravenous canula, baby was premedicated with inj. Glycopyrrolate $(0.005-0.01 \mathrm{mg} / \mathrm{kg})$ and Inj. Fentanyl $(2 \mathrm{mcg} / \mathrm{kg})$. Patients were induced with Inj. Thiopentone $(5-7 \mathrm{mg} / \mathrm{kg})$ and Inj. Succinylcholine $(1-1.5 \mathrm{mg} / \mathrm{kg})$. Intubation was accomplished with appropriate sized non cuffed portex PVC endotracheal tube and anesthesia was maintained with $\mathrm{O}_{2}(50 \%)+\mathrm{N}_{2} \mathrm{O}(50 \%)$ + Sevoflurane and muscle relaxant Inj. Atracurium 0.5 $\mathrm{mg} / \mathrm{kg} \mathrm{I.V}$ as bolus initially then $0.5 \mathrm{mg} / \mathrm{kg} / \mathrm{hr}$ infusion.

At the end of surgery intercostal nerve block/local infiltration of incision line was done by surgeon with inj. Bupivacaine $(2 \mathrm{mg} / \mathrm{kg}$ diluted in normal saline to make concentration $0.25 \%$ ) for postoperative pain relief. Residual muscle paralysis was reversed with inj. Neostigmine $(0.06-0.08 \mathrm{mg} / \mathrm{kg}$ ) plus Inj.glycopyrrolate $(0.005-0.01 \mathrm{mg} / \mathrm{kg})$ and extubation was done after achieving normal muscle activity (limb movement), regular normal respiratory pattern, spontaneous eye opening; otherwise baby was kept intubated and shifted to neonatal ICU for ventilatory management Postoperative recovery, morbidity, duration of hospital stay was noted.

\section{Observations}

In present study 18 patients were enrolled (over a study period of 1 year) but 2 patients left against medical advice before any intervention; finally 16 patients were studied and following observations were noted: 9 patients were admitted in 24 hours of birth while 7 patients were admitted after 1 day of birth in our institute. Patients with age $>1$ day at admission had higher survival rate $(42.86 \%)$ compared to patients with age $\leq 1$ day $(33.33 \%)$ which was found statistically non significant $(\mathrm{p}=0.367)$.

In our study 3 patients had weight $\geq 2.5 \mathrm{Kg}$ and 13 patients had $\leq 2.5 \mathrm{Kg}$. Patients with weight $\geq 2.5 \mathrm{~kg}$ at admission had statistically significant higher survival rate $(100 \%)$ as compared to patients with weight $<2.5$ $\mathrm{kg}(23.08 \%)$. (Table 1)

In our study male and female were equal (8 each) and there was no significant association found between sex of patient and survival rate.
There were 14 patients of $>37$ weeks and 2 patients were $<37$ weeks gestational age and survival rate was higher in patients> 37 weeks $(42.86 \%)$ compared to $<37$ weeks $(0 \%)$ which was statistically insignificant. $(\mathrm{p}=0.375)$

Total 11patients $(68.75 \%)$ were associated with polyhydramnios, out of which 5 patients $(45.45 \%)$ were survived while 5 patients had no association with polyhydramnios in which only 1 patient survived. (statistically insignificant $\mathrm{p}=0.288$ ).

15 patients delivered spontaneously in which 5 patients $(33.33 \%)$ survived, while 1 delivered with caesarian section and survived. Thus Mode of delivery shows no statistically significant association $(\mathrm{P}=$ 0.375 ) with survival.

4 patients were born from primigravida in which only 1 patient $(25 \%)$ survived. 12 patients were born from multigravida in which 5 patients $(41.67 \%)$ survived. Patients born to multigravida mother had higher survival (41.67\%) as compared to patients born to primigravida mother $(25.00 \%)$. Parity of mother had no statistically significant association with survival $(\mathrm{P}=$ $0.396)$.

15 patients had no history of congenital anomalies in family out of which 6 patients survived while only 1 patient had positive family history that was not survived. Thus family history of congenital anomaly had no statistically significant association with survival $(\mathrm{P}=0.625)$.

The survival rate was $27.27 \%$ in patients present with drooling / frothing; $28.57 \%$ in patients with pneumonitis and none in patients with associated congenital anomaly. These clinical findings had no statistically significant association with survival. (Table 2)

In our study 15 patients had type III $b$ of TEF while 1 patient had III a TEF and found no significant correlation with survival.

Patients were grouped as per Waterston's classification and survival was $100 \%$ in Group A, $44.44 \%$ in $\mathrm{Gr} \mathrm{B}$ and $0 \%$ in Group C (statistically significant $\mathrm{P}=0.037$ ). (Table 3)

15 patients were extubated immediately after surgery while 1 patient was shifted intubated in ICU. Delayed extubation showed no statistically significant correlation with survival $(\mathrm{p}=0.194)$

In our study most common postoperative complication was pulmonary $(68.75 \%)$.

The mean duration of hospital stay was more (10.17 days) in patients who survived compared to that did not survive (5.10 days). ( $\mathrm{p}=0.02)$ 
Table 1: Weight of patients

\begin{tabular}{|l|c|c|c|c|c|}
\hline \multirow{2}{*}{ Weight (kg) } & \multicolumn{2}{|c|}{ Survival } & \multicolumn{2}{c|}{ Non-survival } & \multirow{2}{*}{ Total } \\
\cline { 2 - 5 } & No. & \% & No. & \% & \\
\hline$\geq 2.5$ & 3 & 100.00 & 0 & 0.00 & 3 \\
\hline$<2.5$ & 3 & 23.08 & 10 & 76.92 & 13 \\
\hline Total & 6 & & 10 & & 16 \\
\hline
\end{tabular}

$\mathrm{P}=0.036$

Table 2: Clinical presentation (signs and symptoms)

\begin{tabular}{|l|c|c|c|c|c|}
\hline \multirow{2}{*}{ Clinical presentation } & \multicolumn{2}{|c|}{ Survival } & \multicolumn{2}{c|}{ Non-survival } & \multirow{2}{*}{ Total } \\
\cline { 2 - 5 } & No. & \% & No. & \% & \\
\hline Drooling / frothing & 3 & 27.27 & 8 & 72.73 & 11 \\
\hline Inability to feed & 3 & 28.57 & 5 & 71.43 & 8 \\
\hline Crepts/ pneumonitis & 3 & 27.27 & 8 & 72.73 & 11 \\
\hline Congenital anomaly & 0 & 0.00 & 1 & 10.00 & 1 \\
\hline
\end{tabular}

Table 3: Waterston's pre-operative risk classification

\begin{tabular}{|l|l|c|c|c|c|c|}
\hline Group & Criteria & \multicolumn{2}{|c|}{ Survival } & \multicolumn{2}{|c|}{ Non-survival } & Total \\
\cline { 3 - 6 } & & No. & \% & No. & \% & \\
\hline A & Wt. $>2.5 \mathrm{~kg}$ and well & 2 & 100.0 & 0 & 0.00 & 2 \\
\hline B & $\begin{array}{l}\text { Wt. } 1.8-2.5 \mathrm{~kg} \text { OR wt. }>2.5 \mathrm{~kg} \text { assoc. with cong. } \\
\text { anomaly/ mod. pneumonitis }\end{array}$ & 4 & 44.44 & 5 & 55.56 & 9 \\
\hline C & $\begin{array}{l}\text { Wt. }<1.8 \mathrm{~kg} \text { OR Wt. } 1.8-2.5 \mathrm{~kg} \text { assoc. with severe } \\
\text { pneumonitis/ cyanosis cong. Anomaly }\end{array}$ & 0 & 0.00 & 5 & 100.0 & 5 \\
\hline & Total & 6 & & 10 & & 16 \\
\hline
\end{tabular}

$\mathrm{P}=0.037$

\section{Discussion}

TEF is considered a touchstone in pediatric surgery and these cases are usually complicated due to delayed presentation with aspiration of gastric juice or from spillage of secretions or breastfed milk from a blind upper pouch leading to pneumonia, respiratory distress and dehydration. It demands early diagnosis, resuscitation, treatment and emergency surgical correction. Association of congenital anomalies further worsens the outcome

In our study 7 patients were delivered at our hospital while 9 patients were admitted from other hospitals. During this period 16677 deliveries were conducted in our institute which denotes that incidence of babies with TEF was 1:2382 which was comparable to observations made by Yang et $\mathrm{al}^{3}(1: 2400-4500)$ and other studies like Barash et $\mathrm{al}^{1}$ (1:3000).

In our study patients having age at admission $\leq 1$ day were $56.25 \%$ and with age $>1$ day were $43.75 \%$. Survival with age $\leq 1$ day was $33.33 \%$ while it was $42.86 \%$ in $>1$ day age. Calverley et $\mathrm{al}^{4}$ attempted to identify the impact of age at admission in two prospective studies in 1963 and 1968. Age at admission $\leq 1$ day was $32.69 \%$ and $36.14 \%$ respectively in the two studies while it was $67.31 \%$ and $63.60 \%>1$ day. There was no effect of the age at admission on the outcome in either of these studies. Present study also fails to demonstrate any effect of age at admission on the outcome.
In present study male, female ratio was equal (50\% each) and there was no statistically significant difference regarding survival in both sexes, similarly Yang etal ${ }^{3}$ also found no impact of sex of patients on their survival.

In our study $81.25 \%$ patients weighed $<2.5 \mathrm{~kg}$ while $18.75 \%$ patients had weighed $\geq 2.5 \mathrm{~kg}$. Overall survival rate was $66.5 \%$ which was comparable with yang et $\mathrm{al}^{3}(53.33 \%)$, Verma et $\mathrm{al}^{5}(60 \%)$ while survival in $>2.5 \mathrm{~kg}$ wt patient was similar to Fliston et $\mathrm{al}^{6}$ and Calverley et al. ${ }^{4}$

In our study no statically significant association was found between gestational age and survival rate. Since the number of patients with gestational age $<37$ weeks is very small in both our study and Yang et al. ${ }^{3}$ (2 and 3, respectively); no statistically significant conclusion could be drawn whereas, survival in patients with gestational age $\geq 37$ weeks is found to be comparable with other studies. Our results were comparable to Yang et al. ${ }^{3}(80 \%)$ and Fliston et al. ${ }^{6}$ $(59.38 \%)$.

TEF is usually associated with polyhydramnios due to inability of swallowing amniotic fluid by fetus in utero. In present study association of polyhydramnios was $68.75 \%$ and survival rate of babies born to these mothers was $45.45 \%$.Verma et $\mathrm{al}^{5}$ showed that $10 \%$ of mothers had polyhydramnios who delivered baby with TEF.

In our study, $93.75 \%$ babies were delivered by spontaneous vaginal birth, while $6.25 \%$ were delivered by LSCS. Survival rate among spontaneous vaginal 
delivery was $33.33 \%$ and in group of LSCS was $100 \%$ (only single case).Verma et al. ${ }^{5}$ showed that mode of delivery was spontaneous vaginal in $84 \%$ patients and $16 \%$ patients were delivered by LSCS. This difference might be due to obstetrician choice, availability of surgeon and protocols that vary among different institutes.

In our study $25 \%$ of mothers to whom patients of TEF born were primigravida and $75 \%$ mothers were multigravida. Survival rate of neonates, born to primigravida mother was $25 \%$ while it was $41.67 \%$ in multigravida mother. There was no other literature to compare the data.

In our study $6.25 \%$ neonates (one case) had family history of congenital anomaly and this neonate was expired. There was no data available to compare with this observation.

In present study, $68.75 \%$ patients were admitted with drooling of saliva and pneumonitis. Verma et al. ${ }^{5}$ found that $88 \%$ patients had Pneumonitis preoperatively. Ahmed et al., ${ }^{7}$ Fliston et al., ${ }^{6}$ Calverley et al. $^{4}$ found its incidence $52 \%, 43.75 \%$ and $48.2 \%$ respectively.

In our study there was no statistically significant correlation between survival and type of TEF. Yang et al., ${ }^{3}$ Ahmed et al. ${ }^{8}$ and Calverley et al. ${ }^{4}$ also supports our results.

In our study according to Waterston's criteria, patients belonging to Group A were $12.5 \%$, Group B $56.25 \%$ and Group C were $31.25 \%$. Survival rate for Group A, Group B \& Group C patients were 100\%,
$44.44 \%$ and $0 \%$ respectively. These results were comparable to other studies mentioned in Table 4.

In our study survival for Group A and Group B were found to be comparable to other studies while survival was less in Group $\mathrm{C}$ because patients had reported with severe respiratory distress and cyanosis, while in Calverley et $\mathrm{al}^{4}$ study the survival rate in Group A was improved as they have done staged repair which reduces gastric reflux and time to control infections aiding in improvement of neonatal condition.

In our study, $93.57 \%$ of patients were immediately extubated and $6.25 \%$ patients shifted to neonatal ICU intubated. Survival in patients with immediate extubation was $33.33 \%$ and $100 \%$ in patient with delayed extubation (only one patient). The study conducted by Ahmed et $\mathrm{al}^{7}{ }^{9} 95.65 \%$ patients were shifted intubated to ventilator while $14.46 \%$ patients were shifted to ventilator and survival rate was $50 \%$ in study conducted by Calverely et al. ${ }^{4}$ These results concluded that baby having elective ventilatory therapy showed better outcome. In our setup at study time we are not having neonatal ventilatory facility so early extubation and oxygen by hood was in practice.

In our study most common postoperative complications were pulmonary $(68.75 \%)$ which were comparable with Yang et $\mathrm{al}^{3}$ (50\%) and Calverely et al. ${ }^{4}$ $(69.23 \%)$.

In our study mean hospital stay was $10.17 \pm 3.06$ days in survivors as compared to $5.10 \pm 2.28$ days in non-survivors. Verma et al. ${ }^{5}$ reported that mean hospital stay was $18.08 \pm 3$ days in survivors. No other data were available to compare this observation

Table 4: Survival rate in different group in different studies

\begin{tabular}{|l|c|c|c|}
\hline Study & Group & Incidence & Survival \\
\hline Verma et al. (2002) & Group A & $12 \%$ & $66 \%$ \\
& Group B & $56 \%$ & $57 \%$ \\
& Group C & $32 \%$ & $25 \%$ \\
\hline Yang et al. (2003) & Group A & $17.4 \%$ & $100 \%$ \\
& Group B & $47.8 \%$ & $83.3 \%$ \\
& Group C & $34.8 \%$ & $0 \%$ \\
\hline Calverley et al. (1968) & Group A & $18.07 \%$ & $100 \%$ \\
& Group B & $38.55 \%$ & $100 \%$ \\
& Group C & $43.38 \%$ & $59.2 \%$ \\
\hline In our study & Group A & $12.5 \%$ & $100 \%$ \\
& Group B & $56.25 \%$ & $44.44 \%$ \\
& Group C & $31.25 \%$ & $0 \%$ \\
\hline
\end{tabular}

\section{Conclusion}

In present study we conclude that birth weight remains the single most important predictor of mortality among TEF patients as suggested with Waterston's risk classification. Age at admission, sex, gestational age at which baby born, mode of delivery, parity of mother, associated congenital anomalies in family and type of TEF don't have impact on survival of these patients. We suggest that better neonatal ICU facility, trained staff and optimization of neonate before surgery can be a milestone to improve outcome in TEF patients.

\section{Conflicts of Interest: None.}

\section{References}

1. Hall SC and Suresh S. Neonatal anaesthesia. In text book 'Clinical anaesthesia' by Barash PG et al.South asian edition. Wolter Kluwer. Philadelphia. $7^{\text {th }}$ edition, year 2013; p.1178-1215. 
2. Waterston DJ, Carter REB and Aberdeen E. Oesophageal atresia and Tracheo esophageal fistula: A study of survival in 218 infants: Lancet. 1962;1:819-822.

3. Yang F, Soong WJ, Jeng MJ. Esophageal atresia with tracheoesophageal fistula: ten years of experience in an institute. A study of 15 patients enrolled from 1994 to 2003. Patient demographics, associated anomalies and outcomes. China Med Assoc. 2006;69(7):317-321.

4. Calverley RK, Jhonston AE. The anaesthetic management of tracheoesophageal fistula: A review of ten years experience. Can Anesth J. 1972;19:270-281.

5. Verma RK, Nath SS and Sinha GK. Retrospective study of esophageal atresia with Tracheo-esophageal fistula Three year experience. Indian J Anaesth. 2003;47(2):111115.

6. Filston FIC, Rankin JS and Grimm JK. Esophageal atresia; Prognostic factors and contribution of preoperative telescopic endoscopy. Ann Surg. 1984;6:532-536.

7. Ahmed H, Qaisaruddin S, Verma KK. Esophageal atresia and tracheoesophageal fistula. Pakistan Med Journal 1997 (from http://www.pakmednet.com accessed on $1^{\text {st }}$ January 2009).

8. Kirshinger GL, Wolley MM. Esophageal atresia and Tracheo esophageal fistula: 25 years experience and current management. California Med.1969;111(3):165168.

9. Gupta A. Tracheo-oesophageal fistula, oesophageal atresia and anaesthetic management. Indian J Anaesth. 2002;46(5):353-355

10. Memon MI, Ashraf M and Haq A. Our experience of anaesthesia in management of esophageal, atresia and Trcheo esophageal fistula. Ann Pak Inst Med Sci. 2005;1(1):24-26.
11. Gayle JA, Gomez SL, Baluch A, Fox C, Lock S, Kaye A. Anaesthetic consideration for the neonate with tracheoesophagdeal fistula. MEJ Anaesth. 2008(19);12411254

12. Diego MG, Manolo RL. Anaesthetic management of esophageal atresia type III with tracheoesophageal fistula in premature infant without invasive monitoring. $J$ Anaesth Crit Care. 2015;2(4):00063.

13. Bromeling N, Campbell F. Anaesthetic management of congenital tracheoesophageal fistula. Pediatr Anaesth. 2011;21(11):1092-1099.

14. Saade E, Setzer N. Anaesthetic management of tracheoesophageal fistula repair in newborn with hypoplastic left heart syndrome. Pediatr Anaesth. 2006; 16(5):588-590.

15. UlHaq A, Ubaidullah, Akhter N, Samiullah, Javeria, Iftikhar A. Ayub Med Coll Abbottabad. 2009;21(4):129133.

How to cite this article: Pareek S, Raiger L K, Singhal Y. Impact of the various factors on survival of tracheoesophageal fistula patients: A prospective study of 16 patients. Indian J Clin Anaesth. 2018;5(4):620-624. 